\title{
Effect of cross-linking on the performance of polymer inclusion membranes (PIMs) for the extraction, transport and separation of $\mathrm{Zn}$ (II)
}

\author{
Bosirul Hoque ${ }^{\mathrm{a}, \mathrm{b}}$, M. Inês G.S. Almeida ${ }^{\mathrm{a}}$, Robert W. Cattrall ${ }^{\text {a }}$, Thiruvancheril G. Gopakumar ${ }^{\mathrm{b}}$, Spas \\ D. Kolev ${ }^{\mathrm{a} *}$ \\ ${ }^{\text {a }}$ School of Chemistry, The University of Melbourne, VIC 3010, Australia \\ ${ }^{\mathrm{b}}$ Department of Chemistry, Indian Institute of Technology Kanpur, Kanpur 208016, India
}

\begin{abstract}
This study demonstrated the advantages of cross-linking of polymer inclusion membranes (PIMs) in terms of improved stability, rate of extraction and extractive capacity. These advantages were illustrated with the new cross-linked PIM for the selective extraction of $\mathrm{Zn}(\mathrm{II})$, developed as part of this study and containing bis-(2-ethylhexyl)phosphoric acid (D2EHPA) as the carrier (extractant). Three different base-polymers were tested, namely poly(vinyl chloride) (PVC), poly(vinylidene fluoride-cohexafluoropropylene) (PVDF-HFP) and cellulose triacetate (CTA), using poly(ethylene glycol) dimethacrylate (PEG-DMA) as the cross-linking polymer and 2,2-dimethoxy-2-phenyl acetophenone (DMPA) as the initiator. Only PVDF-HFP- and CTA-based PIMs were found to be successful (i.e., homogenous, transparent and mechanically stable). CTA-based PIMs showed a higher extraction rate than the PVDF-HFP-based PIMs and non-cross-linked PIMs containing the same base-polymer, and thus CTA was chosen as the base-polymer for a more detailed study. The effect of the the polymer ratio (CTA:PEG-DMA), concentration of D2EHPA, and concentration of plasticizer (i.e., 2-nitrophenyloctyl ether (NPOE)) on the membrane performance was studied. Best performance in terms of stability, rate of extraction and extractive capacity, which were superior to the corresponding non-cross-linked PIM, was achieved with the cross-linked PIM composed of $40 \mathrm{wt} \%$ D2EHPA, $10 \mathrm{wt} \%$ NPOE, polymers ratio of 6:4 (CTA:PEG-DMA), and 0.6 wt\% DMPA. The PIM surface morphology, examined by atomic force microscopy (AFM), correlated well with the rate of $\mathrm{Zn}(\mathrm{II})$ extraction. It was also demonstrated that the cross-linked PIM could selectively extract $\mathrm{Zn}$ (II) from aqueous solutions at $\mathrm{pH} 3.0$ in the presence of other common base metal ions such as $\mathrm{Cd}(\mathrm{II}), \mathrm{Co}(\mathrm{II}), \mathrm{Cu}(\mathrm{II})$, and $\mathrm{Ni}(\mathrm{II})$ in concentrations 5 times higher than that of $\mathrm{Zn}(\mathrm{II})$. Interference from $\mathrm{Fe}(\mathrm{III})$ was removed by precipitation with phosphate.

The newly developed PIM transported practically all $\mathrm{Zn}$ (II) from a feed solution at $\mathrm{pH} 3$ to a $1.0 \mathrm{M} \mathrm{HCl}$ receiving solution as a result of the simultaneous extraction and back-extraction of $\mathrm{Zn}$ (II) at the corresponding PIM/solution interfaces, and the facilitated transport of $\mathrm{Zn}(\mathrm{II})$ across the membrane.
\end{abstract}

Keywords: polymer inclusion membrane (PIM); bis-(2-ethylhexyl)phosphoric acid (D2EHPA); poly(ethylene glycol) dimethacrylate; cross-linking; zinc(II) extraction and transport

\footnotetext{
*Corresponding author: E-mail address: s.kolev@unimelb.edu.au
} 


\section{Introduction}

Emerging as a potential alternative to traditional solvent extraction, separation based on polymer inclusion membranes (PIMs), consisting of a base-polymer, carrier (extractant) and plasticizer or modifier in some cases, has been attracting increased attention in recent years [1]. The main reason behind this trend is based on the better stability of PIMs than supported liquid membranes (SLMs) which are the most frequently used liquid membranes at present [1-10]. Despite the better stability of PIMs [1, 11], their robustness is still considered insufficient for applications on an industrial scale. Hence, recent research on PIMs has also been focused on further improving their stability together with other performance characteristics such as rate of extraction and extractive capacity.

The limited stability of PIMs is mainly caused by the loss of membrane liquid phase, composed of the PIM carrier and plasticizer or modifier (if used), to the aqueous phase(s) (i.e., feed and receiving solutions) in contact with the membrane [12-14]. The factors, responsible to a great extent for the leaching of the membrane liquid phase, include (1) problems associated with the miscibility of the membrane components [15], (2) solubility of the membrane liquid phase in the aqueous phase(s) $[16,17]$, and (3) the composition of the aqueous phase(s) in contact with the membrane $[10,13]$. Different approaches have been proposed with the aim to eliminate or minimise the effect of these three factors. Recently, Kaya et al. have demonstrated improvement of the PIM mechanical stability by doping the membrane with reduced graphene oxide (rGO) without compromising its permeability [18]. According to the authors, the addition of rGO to the membrane composition improved its structure, increased its roughness and also prevented the physical aging of the membrane. Salazar-Alvarez et al. reported on the use of ethanol as a modifier, which was added to the casting solution and resulted in better miscibility of the membrane components (i.e., bis-(2-ethylhexyl)phosphoric acid (D2EHPA), tris-(2-butoxyethyl)phosphate and cellulose triacetate (CTA)) [15]. Matsuoka et al. reduced the loss of the carrier tributyl phosphate (TBP) from the corresponding PIMs by saturating the feed solution with TBP [17]. It was also demonstrated by Cho et al. that the membrane stability could be improved by incorporating in the membrane composition a modifier with very low water solubility [16]. The ionic strength of the aqueous feed or receiving solutions also plays a determining role in the loss of membrane liquid phase, and it has been reported by Zhang et al. that the membrane mass loss during extraction could be minimized by conditioning the PIM in an aqueous solution with the same background composition as the feed solution for a certain period of time [13]. Recently a new approach has been developed by us for improving the stability as well as the permeability of PIMs which is based on introducing an additional polymer, capable of creating a cross-linked polymer network in the presence of UV-light [19].

Cross-linking polymers are extensively used engineering materials because of their excellent mechanical and thermal stability [20]. There are two common approaches used to induce the cross-linking, i.e., thermal polymerisation or photo-initiated radical polymerisation. Radiation induced polymerisation has some advantages over heat induced polymerisation, which include high reaction rate at ambient temperature, low energy consumption and solvent free formulation [21]. There are several polymers that can be used as crosslinking agents, namely poly(ethylene glycol) dimethacrylate (PEG-DMA) [22, 23], 4-hydroxy-butyl vinyl ether (HBVE), bismaleimide (Q-bond) [24], and oxetane-acrylate [21]. PEG-DMA is among the most 
frequently used cross-linking polymers with numerous applications in biochemistry and medicinal chemistry [25-27]. Its capability in improving mechanical resistance under high vacuum conditions or under chemical stress is well known [28]. Engineered mechanical properties and biodegradability of this polymer make it suitable for orthopaedic tissue engineering [29].

Hence, this cross-linking polymer was chosen for the present study which focused on utilising the cross-linking polymerisation concept in the development of a more stable PIM for the extraction, transport and separation of $\mathrm{Zn}$ (II) with improved extraction rate and capacity. The compatibility of different base-polymers with the cross-linking polymer PEG-DMA was investigated using D2EHPA as the carrier. The long-term stability and surface morphology of the PIMs studied were also examined.

\section{Experimental}

\subsection{Reagents and solutions}

D2EHPA (97\%, Aldrich, USA) as the carrier (extractant) was used as received in the preparation of all membranes. Three different polymers, i.e., poly(vinylidene fluoride-co-hexafluropropylene) (PVDF-HFP, Aldrich, USA), CTA (Acros Organics, USA) and PVC (Aldrich, USA), were tested as base-polymers. PEGDMA (Aldrich, USA) and 2,2-dimethoxy-2-phenyl acetophenone (DMPA, Aldrich, Italy) were used as the cross-linking polymer and the initiator, respectively. NPOE (Sigma-Aldrich, Switzerland) was used as the plasticizer in the CTA- and PVC-based PIMs. The plasticizer dibutyl phthalate (DBP, Aldrich, USA) was also used for PVC-based PIM preparation only. Tetrahydrofuran (THF without stabiliser, VWR) and dichloromethane (DCM, Chem-supply) were of analytical reagent grade and were used in the preparation of the PIM casting solutions.

Zinc(II) chloride (Unilab, APS chemical limited, Australia) and hydrochloric acid (Ajax, Australia) were of analytical reagent grade and were used in the preparation of solutions for the extraction, back-extraction and transport experiments. For the selectivity studies, the following reagents were used: nickel(II) chloride (Sigma Aldrich, USA), cadmium(II) chloride (UNIVAR, Ajax chemicals, Australia), copper(II) chloride (UNIVAR, Ajax chemicals, Australia), cobalt(II) chloride (J.T. Baker chemicals, USA), and disodium hydrogen phosphate (BDH chemicals, UK). All aqueous solutions were prepared using deionised water (resistivity $\geq 18 \mathrm{M} \Omega \mathrm{cm}$, Millipore, Synergy 185).

\subsection{Membrane preparation}

Cross-linked PIMs containing PVDF-HFP as the base-polymer were prepared by mixing a weighed amount of this polymer with THF in a glass jar ( $1 \mathrm{~mL}$ of solvent per $0.1 \mathrm{~g}$ of base-polymer), followed by stirring the mixture at $40{ }^{\circ} \mathrm{C}$ using a temperature-controlled water-bath. After complete dissolution of the base-polymer, D2EHPA was added, and the mixture was stirred once again at $40{ }^{\circ} \mathrm{C}$ until a homogeneous solution was obtained. After cooling to room temperature, PEG-DMA and DMPA were added to the solution. Since both the cross-linking polymer and the photo-initiator are light sensitive, the glass jar containing the casting solution was covered with aluminium foil and stirred for another $30 \mathrm{~min}$ at room temperature. The resultant PIM casting solution was cast on a clean, smooth glass plate using a homemade Teflon casting knife [30]. The PIM casting 
solution was poured into the casting knife well which was subsequently pulled across the glass plate to form a thin layer of the PIM casting solution. The glass plate was covered with an aluminium tray $(27.0$ by $32.5 \mathrm{~cm}$ and $9.5 \mathrm{~cm}$ tall) to allow the slow evaporation of THF for a $24 \mathrm{~h}$ period thus assisting the formation of homogeneous PIMs.

Cross-linked PIMs containing PVC or CTA as the base-polymer were prepared by first dissolving the basepolymer in THF or DCM at room temperature under stirring until a homogenous casting solution was obtained. The remaining components, namely D2EHPA, PEG-DMA, DMPA, and NPOE or DBP, were then added to the casting solution and the solution was stirred at room temperature until complete dissolution of all PIM components was achieved which was followed by PIM casting as described above.

The resulting rectangular-shaped membranes (approximately $14 \times 12 \mathrm{~cm}$ ) were peeled from the glass plate. Only flexible, mechanically stable and homogeneous PIMs were considered as successful and selected to undergo UV treatment as described in Section 2.3. Non-cross-linked PIMs were prepared using the same procedure as described above, except that no PEG-DMA and DMPA were added to the PIM casting solution and no UV treatment was applied.

\subsection{UV-polymerization}

In order to cross-link the membranes a house-made UV-treatment box was used (Figure 1). The UV-treatment box consisted of two steel compartments. One of them contained the UV-lamp (UVP-USA, $8 \mathrm{~W}, 0.16$ A, 230 $\mathrm{V}$, tuned at $365 \mathrm{~nm})$ (Figure $1 \mathrm{~A})$, and on top of it a glass plate $(27 \times 20 \mathrm{~cm}, 2 \mathrm{~mm}$ thickness) and a membrane holder were placed (Figure 1B). The other compartment acted as the lid of the box and accommodated an inlet and outlet for $\mathrm{N}_{2}$ gas (Figure 1C). The membrane holder (Figure 1B) was composed of two metallic frames $(25 \times 19 \mathrm{~cm}$ each, wrapped in aluminium foil) which were used to hold the rectangular-shaped PIM. The glass plate was used to support the membrane holder over the UV lamp. The total distance between the UV lamp and the PIM was $7.3 \mathrm{~cm}$. Since $\mathrm{O}_{2}$ also absorbs UV-light at $365 \mathrm{~nm}, \mathrm{~N}_{2}$ gas was pumped into the UV-treatment box for $15 \mathrm{~min}$ in order to purge the air. The UV-lamp was then switched on and the PIM was irradiated for 15 min while pumping $\mathrm{N}_{2}$ gas [19].

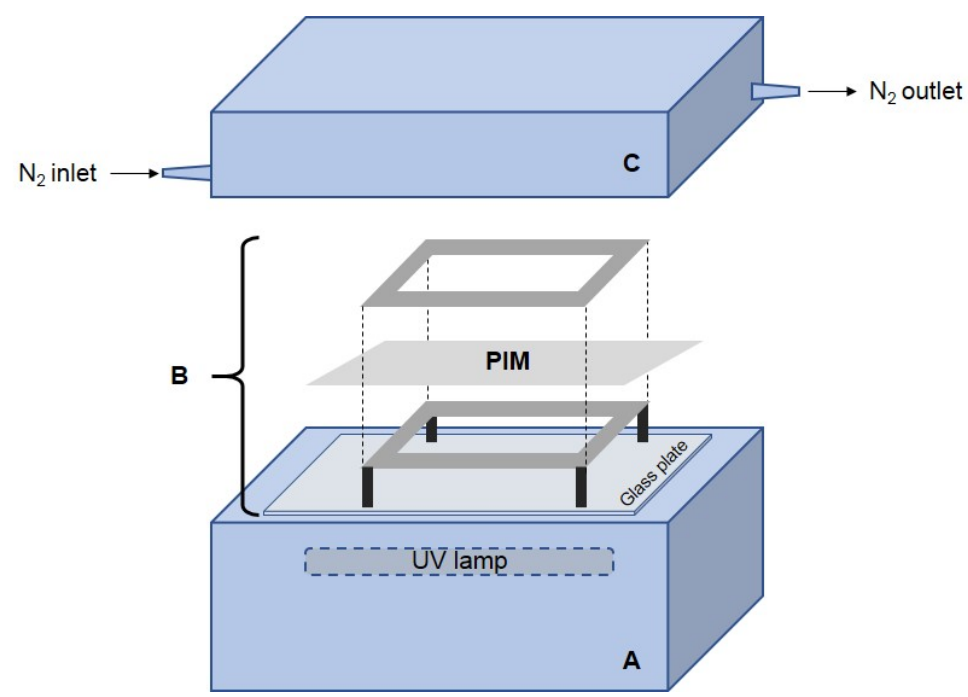

Figure 1. Schematic of the UV-treatment box. (A) Compartment accommodating the UV lamp; (B) Membrane holder placed on top of a glass plate; (C) Lid of the box with a $\mathrm{N}_{2}$ inlet and outlet. 


\subsection{Zn(II) extraction, back-extraction and transport experiments}

A $30 \mathrm{mg} \mathrm{L}^{-1} \mathrm{Zn}$ (II) solution (prepared from $\mathrm{ZnCl}_{2}$ ), adjusted to $\mathrm{pH} 3$ using $1.0 \mathrm{M} \mathrm{HCl}$, was used as the feed solution, and $1.0 \mathrm{M} \mathrm{HCl}$ was used as the receiving (stripping) solution for the extraction and back-extraction of $\mathrm{Zn}(\mathrm{II})$. These conditions have been adopted because they were found to be the optimal conditions for the selective and efficient extraction and back-extraction of $\mathrm{Zn}$ (II) using a PIM containing D2EHPA as the carrier [31]. A house-made holder, made of a $3 \mathrm{~mm}$ thick PVC sheet (supplied by Alternative plastics Australia Pty Ltd), was used to hold the membranes vertically inside the aqueous feed and receiving solutions to prevent the membrane from folding or attaching to the glass jar walls during the extraction and back-extraction experiments. Circular pieces of the cross-linked or non-cross-linked PIMs (3.65 cm diameter, average mass between $60-80 \mathrm{mg}$ ) were thus attached to holders and immersed in glass jars containing $100 \mathrm{~mL}$ of the feed or receiving solutions followed by shaking at $150 \mathrm{rpm}$ using an orbital shaker (Platform Mixer OM06, Ratek, Australia). During the extraction and back-extraction experiments, $0.5 \mathrm{~mL}$ samples were collected at preselected time intervals and diluted prior to the determination of the $\mathrm{Zn}$ (II) concentration by atomic absorption spectrometry (AAS). All the experiments were done in triplicate.

The initial flux $\left(J_{0}\right)$ was calculated according to the method developed by St. John et al. [32]. An exponential decay function (Eq. (1)) was used to fit the transient $\mathrm{Zn}$ (II) concentration in the aqueous feed solution, and the initial flux was calculated from the first derivative (Eq. (2)) of the best exponential fit (Eq. (1)). All these calculations were executed with the help of a home-made Quick C program.

$$
\Psi=a_{1}+a_{2} e^{-a_{3} t}
$$

where $a_{1}, a_{2}$ and $a_{3}$ are the empirical coefficients of Eq. (1) best fitting the experimental data.

$$
J_{0}=\left(\frac{d \Psi}{d t}\right)_{\mathrm{t}=0}=-a_{2} a_{3}
$$

Transport experiments involving the simultaneous extraction and back-extraction of $\mathrm{Zn}(\mathrm{II})$ on each side of the PIM with best extraction performance were carried out in a glass transport cell consisting of two $100 \mathrm{~mL}$ compartments (i.e., feed and receiving compartment) separated by the PIM with a surface area exposed to the feed and receiving solutions of $18.1 \mathrm{~cm}^{2}$ (diameter of $4.8 \mathrm{~cm}$ ) (Figure 2). The membrane was sandwiched between the two compartments with the assistance of Teflon gaskets. Transport experiments involving feed solutions with three different $\mathrm{Zn}$ (II) concentrations (i.e., 27, 46 and $65 \mathrm{mg} \mathrm{L}^{-1} \mathrm{Zn}$ (II)) and a receiving solution containing 1.0 M HCl were conducted. During the transport experiments, both the feed and receiving solutions were stirred at $1200 \mathrm{rpm}$ (measured by a laser tachometer, Digitech QM1448, Jaycar, Australia) using glass stirrers. Samples of $0.5 \mathrm{~mL}$ were collected from the feed and receiving solutions at predetermined times and replaced with the same volume of deionised water or $1.0 \mathrm{M} \mathrm{HCl}$, respectively. The collected samples were then diluted with deionised water and their Zn(II) concentrations were measured by AAS. 


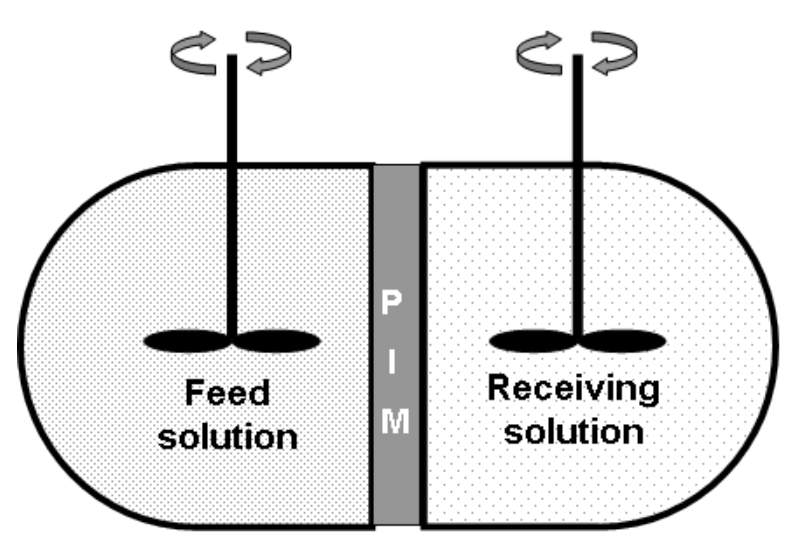

Figure 2. Schematic of the PIM transport cell.

\subsection{Instrumentation}

The Zn(II) concentration in all feed and receiving solutions was determined by AAS (Hitachi Z-2000 Series Polarized Zeeman, Japan) with the following settings: Zn hollow cathode lamp (Hitachi); current, $8 \mathrm{~mA}$; working wavelength, $213.9 \mathrm{~nm}$; burner height, $7 \mathrm{~mm}$; slit width, $0.7 \mathrm{~nm}$; acetylene flow rate, $1.8 . \mathrm{L} \mathrm{min}^{-1}$; and air flow rate, $15.0 \mathrm{~L} \mathrm{~min}^{-1}$.

Inductively coupled plasma-optical emission spectrometry (ICP-OES) (Optima 4300 DV, PerkinElmer, USA) was used to determine the transient concentrations of $\mathrm{Zn}(\mathrm{II}), \mathrm{Co}(\mathrm{II}), \mathrm{Cu}(\mathrm{II}), \mathrm{Ni}(\mathrm{II}), \mathrm{Cd}(\mathrm{II})$, and $\mathrm{Fe}(\mathrm{III})$ in the feed solutions used in the selectivity study. The instrumental set up was: power level, $1.30 \mathrm{Kw}$; coolant flow, 15.0 $\mathrm{L} \mathrm{min}^{-1}$; auxiliary flow, $0.20 \mathrm{~L} \mathrm{~min}^{-1}$; nebulizer flow, $0.80 \mathrm{~L} \mathrm{~min}^{-1}$; and sample aspiration rate, $1.50 \mathrm{~mL} \mathrm{~min}^{-1}$.

The $\mathrm{pH}$ of the feed and receiving solutions was measured before and after each experiment using a combined $\mathrm{pH} /$ conductivity meter (SmartChem-Lab, TPS, Australia).

Membrane thickness was measured using an optical microscope (LH50A, Olympus, Japan) with a calibrated Nikon lens (Carton Optical Ind., Japan). Circular membranes were cut in half and the thickness of the crosssection was measured at ten different points.

The mass of each membrane was measured using an analytical balance before each extraction experiment. In the stability study, membrane mass was also measured after drying the membrane overnight following each extraction/back-extraction cycle.

Mass spectra of the feed and receiving solutions were obtained by Accurate-Mass Q-TOF Liquid Chromatography Mass Spectrometer (Agilent Technologies, USA). Standard solutions were prepared by dissolving weighted amounts of PEG-DMA, D2EHPA and NPOE in acetonitrile (Ajax, Australia) and deionised water.

\subsection{Surface morphology study}

The surface morphology of UV-treated and non-treated PIMs was studied by atomic force microscopy (AFM, Asylum Research, Oxford Instruments). The AFM study was performed using a Si tip with force constant 1.2$29 \mathrm{~N} \mathrm{~m}^{-1}$. The resonance frequency of the cantilever during the imaging was $\approx 138 \mathrm{kHz}$. The relative humidity $(58-60 \%)$ and temperature $\left(21-23{ }^{\circ} \mathrm{C}\right)$ of the experimental room were monitored during the imaging period. Image processing and roughness calculations were conducted with WSxM 5.0 software (Nanotech). 


\section{Result and discussion}

\subsection{Selection of the base-polymer}

Although the base-polymer is not the active constituent of a PIM, it plays an important role in determining its properties as it provides the back-bone of the membrane which holds the carrier within its structure. The PIM's performance depends on the compatibility between the base-polymer, the membrane liquid phase and, in the case of cross-linked PIMs, also on the nature of the cross-linking polymer. Hence, three different basepolymers, namely PVC, CTA and PVDF-HFP, were used to cast cross-linked and non-cross-linked PIMs containing $35 \mathrm{wt} \%$ D2EHPA to assess their ability to form homogeneous and mechanically stable PIMs with oil-free surfaces. It was observed that the surfaces of the cross-linked PVC- and CTA-based PIMs were oily (i.e., unsuccessful PIMs) and the PVDF-HFP-based PIM was homogenous and with oil-free surfaces (i.e., successful PIM). Since, PIMs containing only D2EHPA and PVC are well known to produce good membranes [1], this oil formation on the PIMs' surfaces suggested an incompatibility between the polymers which is likely due to the difference in their polarities. A plasticizer was thus added to the cross-linked PVC- and CTA-based membranes. NPOE was chosen because it is one of the most commonly used plasticizers in PIMs due to its low viscosity $\left(11.1 \mathrm{cP}, 25^{\circ} \mathrm{C}[1]\right)$ and high dielectric constant $\left(\varepsilon_{\mathrm{r}}=24,25{ }^{\circ} \mathrm{C}\right.$ [1]). The cross-linked PIM with CTA and NPOE (20 wt\%) was homogenous and with oil-free surfaces and was thus considered to be successful and studied further. However, the cross-linked PVC-based membrane still had an oily surface in the presence of $20 \mathrm{wt} \%$ NPOE. DBP was also tested as plasticizer $\left(\varepsilon_{\mathrm{r}}=6.58,20{ }^{\circ} \mathrm{C}\right.$ [1] $)$ to cast PVC-based cross-linked membranes, although these were also oily and thus PVC-based membranes were not considered for further studies. The corresponding non-cross-linked PVC- and CTA-based PIMs were considered as successful because they were homogeneous, stable and with oil-free surfaces.

As both CTA (with NPOE) and PVDF-HFP base-polymers allowed the formation of successful cross-linked PIMs, a comparison between cross-linked and non-cross-linked PIMs was conducted with respect to their ability to extract $\mathrm{Zn}(\mathrm{II})$. The results of extraction experiments, expressed as $\mathrm{mg}$ of $\mathrm{Zn}(\mathrm{II})$ extracted per $1 \mathrm{~g}$ of PIM versus time, are presented in Figure 3. The cross-linked CTA-based PIM extracted Zn(II) at a faster rate in comparison with its non-cross-linked counterpart (Figure 3a), whereas the same was not observed for the PVDF-HFP-based membranes (Figure 3b). Moreover, the rate of extraction of $\mathrm{Zn}$ (II) into the cross-linked CTA-based membrane was higher than that for the cross-linked PVDF-HFP-based PIM. Therefore, CTA was selected as the base-polymer in the subsequent experiments.

The results presented in Figure 3 suggest that cross-linking affects in a different way the structure of CTA and PVDF-HFP-based PIMs. However, this structure is also strongly dependent on the PIM carrier. In addition to the structural factors, the rate of extraction and transmembrane transport are also determined by the nature of the extracted chemical species-carrier adduct (e.g., ion-pair or complex) and the characteristics of the PIM liquid phase (i.e., viscosity, dielectric constant). Previously reported results on the comparison of cross-linked and non-cross-linked PIMs containing PVDF-HFP as the base-polymer and Aliquat 336 as the carrier in the extraction of $\mathrm{SCN}^{-}$showed that the cross-linked PIM performed considerably better than its non-cross-linked counterpart [19]. This phenomenon was explained by the presence of hydrophilic PEG groups whose hydration 
could have led to the creation of water channels within the membrane assisting the transmembrane transport of the ion-pairs of the quaternary alkylammonium cations of Aliquat 336 and $\mathrm{SCN}^{-}$. However, in the case of the extraction and transport of the hydrophobic Zn(II)-D2EHPA complex, these water channels are unlikely to provide any advantages and hence the performance of the PVDF-HFP cross- and non-cross-linked PIMs was found to be similar (Figure 3b). However, it can be hypothesized that cross-linking of the CTA-based PIMs containing D2EHPA as carrier induces bulk or surface structural changes which are beneficial to their performance. The beneficial effects on $\mathrm{Zn}$ (II) extraction and transport of the surface morphology of the crosslinked CTA-based PIMs are discussed in Section 3.4.
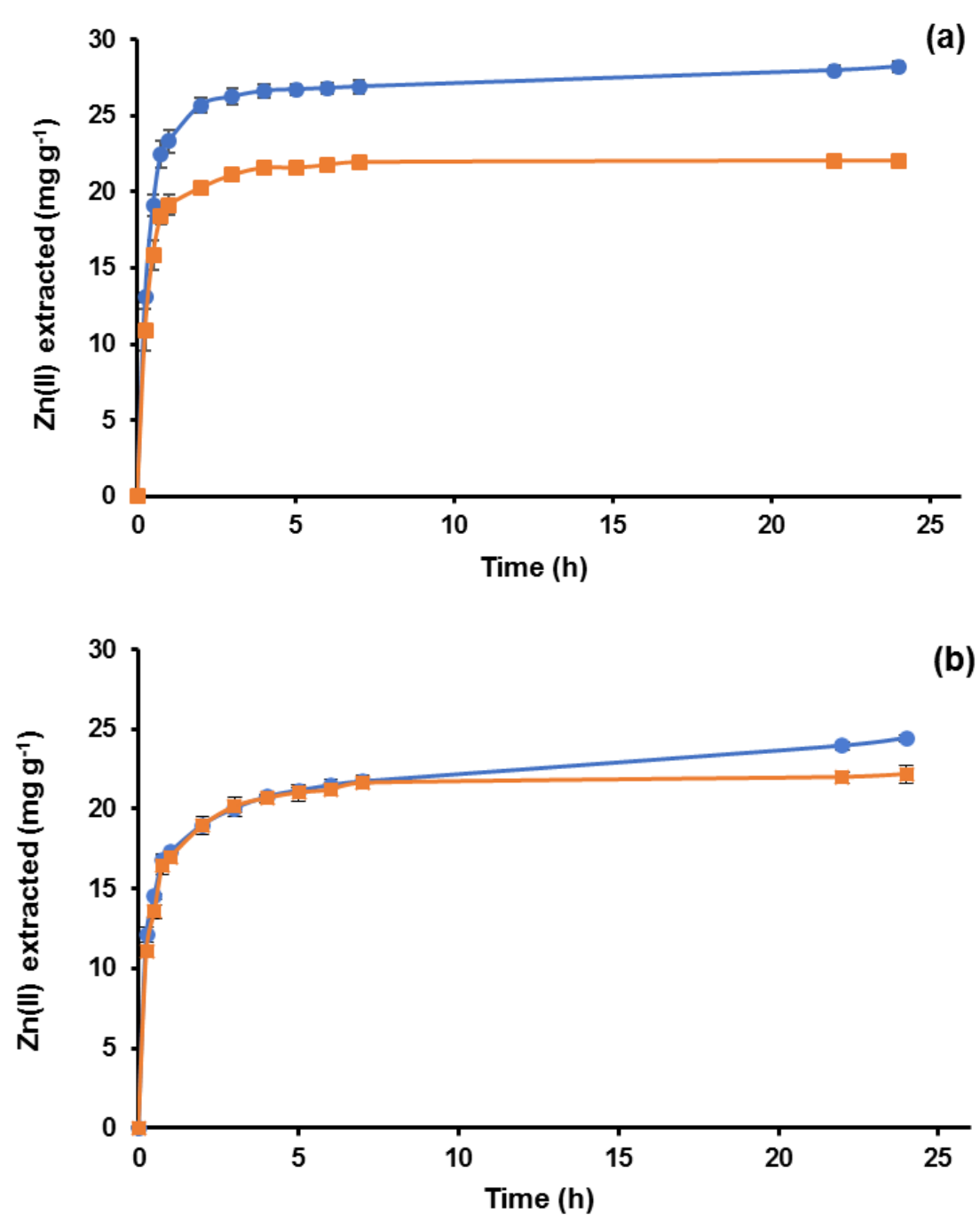

Figure 3. Transient concentration of Zn(II) extracted (expressed as mg Zn per g of PIM) into cross-linked (•) or non-cross-linked ( $\square$ ) PIMs composed of $35 \mathrm{wt} \%$ D2EHPA as the carrier (extractant) and CTA (a) or PVDFHFP (b) as the base-polymer. Polymer ratio, 6:4; NPOE concentration in the CTA-based PIMs, $20 \mathrm{wt} \%$; feed solution, $100 \mathrm{~mL}$ of $30 \mathrm{mg} \mathrm{L}^{-1} \mathrm{Zn}(\mathrm{II})$ at $\mathrm{pH}$ 3; PIMs thicknesses: CTA-crosslinked - 54 $\pm 2 \mu \mathrm{m}$, CTA-noncrosslinked - 55 $\pm 2 \mu \mathrm{m}$, PVDF-HFP-crosslinked - 46 $\pm 3 \mu \mathrm{m}$, and PVDF-HFP-non-crosslinked - $44 \pm 3 \mu \mathrm{m}$. Error bars, \pm standard deviation (SD) based on 3 replicate experiments $(n=3)$.

With the aim of proving that the extractant was the PIM component responsible for the extraction of $\mathrm{Zn}(\mathrm{II})$, a blank experiment was also conducted using a CTA-based cross-linked membrane with a composition identical 
to the one described above with the exception that no carrier (i.e., D2EHPA) was added. The result obtained (Figure S1, Supplementary Material) indicated that no $\mathrm{Zn}(\mathrm{II})$ was transferred from the solution to the PIM. Therefore, it was concluded that the transfer of $\mathrm{Zn}$ (II) from the solution to the PIM was the result of its extraction by the PIM carrier (i.e., D2EHPA).

\subsection{Effect of CTA-based cross-linked membrane composition on Zn(II) extraction}

\subsubsection{Effect of the polymer ratio (CTA:PEG-DMA)}

The ratio between the cross-linking polymer and the base-polymer form the backbone of the cross-linked PIM within which the carrier was held was found to affect the properties of the corresponding PIM [19]. Therefore, it was essential to study the effect of the polymer ratio CTA:PEG-DMA in order to achieve satisfactory extraction performance. Extraction experiments were thus conducted with cross-linked PIMs with a ratio of CTA to PEG-DMA varying from 5:5 to 9:1, while maintaining all other conditions (i.e., $35 \mathrm{wt} \%$ D2EHPA, 20 $\mathrm{wt} \%$ NPOE, $0.6 \mathrm{wt} \%$ initiator, $15 \mathrm{~min}$ of UV-treatment, feed solution containing $30 \mathrm{mg} \mathrm{L}^{-1} \mathrm{Zn}$ (II) at $\mathrm{pH} 3$ ) constant. Increasing the amount of PEG-DMA, so that it was higher than the amount of the base-polymer CTA, was found to compromise the membrane's mechanical stability. A similar observation, using PVDF-HFP as the base-polymer, was also reported by O'Bryan et al. [19]. The results obtained in extraction experiments are shown in Figure 4, where it can be observed that the PIMs with 5:5 and 6:4 polymer ratios exhibited the highest extraction rates, while the extraction rates of the other PIMs were $20 \%$ lower. The higher extraction rates for ratios 5:5 and 6:4 were probably caused by the higher degree of cross-linking. The polymer ratio 6:4 was selected for the subsequent experiments since the PIM with the polymer ratio 5:5 was slightly sticky and softer before UV-treatment in comparison with the PIMs with the former polymer ratio. It was also observed that the initial flux for the PIM with 6:4 polymer ratio was slightly higher than the one for the PIM with 5:5 polymer ratio (14.8 and $13.4 \mu \mathrm{mol} \mathrm{m} \mathrm{m}^{-2} \mathrm{~s}^{-1}$, respectively).

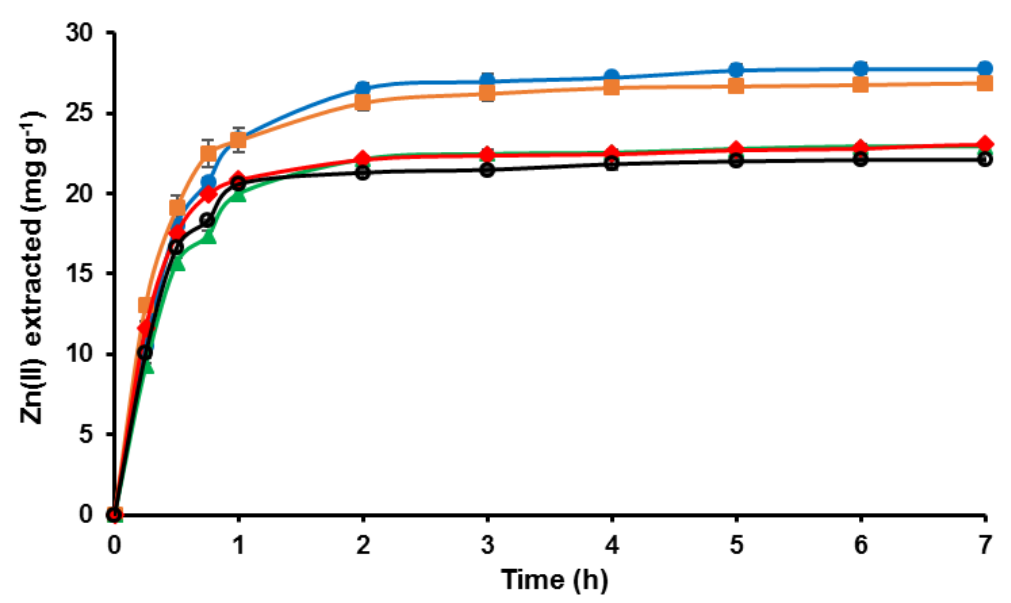

Figure 4. Effect of the ratio between CTA and PEG-DMA on the transient concentration of Zn(II) extracted

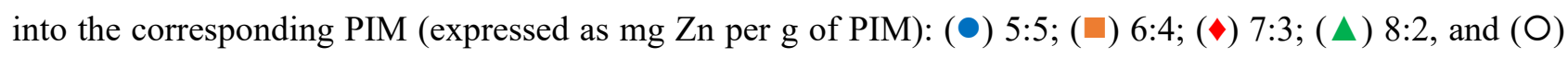
9:1. PIM composition, $35 \mathrm{wt} \%$ D2EHPA, $20 \mathrm{wt} \%$ NPOE, $0.6 \%$ initiator; feed solution, $100 \mathrm{~mL}$ of $30 \mathrm{mg} \mathrm{L}^{-1}$ $\mathrm{Zn}(\mathrm{II})$ at $\mathrm{pH}$ 3; PIMs thicknesses varied between 50 and $55 \mu \mathrm{m}$ (Table S1, Supplementary Material). Errors bars, $\pm \operatorname{SD}(n=3)$. 


\subsubsection{Effect of the membrane liquid phase composition}

As mentioned in the Introduction, PIM instability is associated with the loss of membrane liquid phase. In the present study the membrane liquid phase consisted of the extractant D2EHPA and the plasticizer NPOE. Hence, it was important to study the effect of their concentrations in order to obtain a PIM composition which produced stable PIMs with good extraction capabilities. The effect of the membrane liquid phase was thus studied by casting PIMs with different concentrations of D2EHPA (35-50 wt\%) and NPOE (5-20 wt\%), as shown in Table 1. Those PIM compositions that produced successful membranes (i.e., homogenous, transparent and mechanically stable) were then used in the $\mathrm{Zn}$ (II) extraction experiments, and the performance of the corresponding PIMs was assessed according to the amount of $\mathrm{Zn}$ (II) extracted (Table 1).

Table 1. Effect of the membrane liquid phase composition of the cross-linked CTA-based PIM on its appearance and extractive capacity. The concentrations of the carrier (i.e., D2EHPA) and plasticizer (i.e., NPOE) were varied while keeping the polymer ratio at 6:4 (CTA:PEG-DMA) and the initiator concentration at $0.6 \mathrm{wt} \%$. Successful PIMs were used in the extraction and back-extraction experiments for a $24 \mathrm{~h}$ period. The concentrations of $\mathrm{Zn}(\mathrm{II})$ in the PIMs $\left(\mathrm{mg} \mathrm{g}^{-1}\right)$ at equilibrium are also presented.

\begin{tabular}{|c|c|c|c|c|c|}
\hline PIM ID & $\begin{array}{l}\text { D2EHPA } \\
(w t \%)\end{array}$ & $\begin{array}{l}\text { NPOE } \\
(w t \%)\end{array}$ & $\begin{array}{l}\text { PIM's physical } \\
\text { appearance } \\
\text { before } \\
\text { extraction }\end{array}$ & $\begin{array}{l}\text { PIM's physical } \\
\text { appearance } \\
\text { after back- } \\
\text { extraction }\end{array}$ & $\begin{array}{l}\mathrm{Zn}(\mathrm{II}) \text { extracted } \\
\text { at equilibrium } \\
\left(\mathrm{mg} \mathrm{g}^{-1}\right)\end{array}$ \\
\hline 1 & 35 & 5 & $\checkmark$ & $\checkmark$ & $26.0( \pm 0.3)$ \\
\hline 2 & 35 & 10 & $\checkmark$ & $\checkmark$ & $24.0( \pm 0.3)$ \\
\hline 3 & 35 & 20 & $\checkmark$ & $\checkmark$ & $28.2( \pm 0.4)$ \\
\hline 4 & 40 & 5 & $\checkmark$ & $\checkmark$ & $31.6( \pm 0.1)$ \\
\hline 5 & 40 & 10 & $\checkmark$ & $\checkmark$ & $31.1( \pm 0.2)$ \\
\hline 6 & 40 & 20 & $\checkmark$ & $\checkmark$ & $28.6( \pm 0.3)$ \\
\hline 7 & 45 & 5 & $\checkmark$ & $\begin{array}{l}\text { Deformed and } \\
\text { white in color }\end{array}$ & $36.5( \pm 0.7)$ \\
\hline 8 & 45 & 10 & $\checkmark$ & $\begin{array}{l}\text { Deformed and } \\
\text { white in color }\end{array}$ & $34.5( \pm 0.2)$ \\
\hline 9 & 45 & 20 & $\checkmark$ & NT & $31.9( \pm 1.3)$ \\
\hline 10 & 50 & 5 & $\begin{array}{l}\text { Non- } \\
\text { homogenous }\end{array}$ & NT & NT \\
\hline 11 & 50 & 10 & $\begin{array}{l}\text { Non- } \\
\text { homogenous }\end{array}$ & NT & NT \\
\hline 12 & 50 & 20 & $\begin{array}{l}\text { Non- } \\
\text { homogenous }\end{array}$ & NT & NT \\
\hline
\end{tabular}

$\checkmark$ Successful PIM (i.e., homogenous, transparent and mechanically stable); NT, PIM not tested, 
All membranes cast with $50 \mathrm{wt} \%$ D2EHPA (Table 1, PIMs 10, 11 and 12) were not homogenous and for that reason were not considered as successful for further study. Membranes with 35, 40 or $45 \mathrm{wt} \%$ D2EHPA and 5,10 or $20 \mathrm{wt} \%$ NPOE (Table 1, PIMs 1 to 9) were found to be successful and were assessed for their ability to extract $\mathrm{Zn}$ (II). PIMs with $45 \mathrm{wt} \%$ D2EHPA and with 5 or $10 \mathrm{wt} \%$ NPOE (Table 1, PIMs 7 and 8) were more efficient in extracting $\mathrm{Zn}$ (II) than the remaining successful PIMs. It was observed that, after backextraction with $1.0 \mathrm{M} \mathrm{HCl}$ solution (i.e., receiving solution), these PIMs started to become opaque. The PIMs containing $40 \mathrm{wt} \%$ D2EHPA and 5 or $10 \mathrm{wt} \%$ NPOE (Table 1, PIMs 4 and 5), and $45 \mathrm{wt} \%$ D2EHPA and $20 \mathrm{wt} \%$ NPOE (Table 1, PIM 9) were all able to extract about $31 \mathrm{mg}$ of Zn(II) per g of membrane. PIMs 4 and 5 exhibited the same extraction efficiency as PIM 9 but contained lower concentrations of D2EHPA and NPOE and therefore were selected for the subsequent stability study.

\subsection{Stability study}

Both PIMs 4 and 5 (Table 1) were used in 5 consecutive extraction and back-extraction experiments (i.e., 5 cycles) to assess their long-term stability. It was observed that after the second cycle, PIM 4 started to become opaque as a precipitate started to form on the PIM's surface, whereas no such formation was observed for PIM 5 throughout the 5 cycles. Therefore, PIM 5 was selected as the PIM composition with best extraction performance for further studies in which its stability was compared with that of non-cross-linked PIMs.

The superior stability of cross-linked PIMs containing PVDF-HFP as the base-polymer and Aliquat 336 as the extractant in comparison with the corresponding non-cross-linked PIMs has been demonstrated earlier by us in 5 consecutive extraction/back-extraction experiments [19]. Similarly, the cross-linked CTA-based PIM (PIM 5, Table 1) and its non-cross-linked counterpart were used in five consecutive extraction/back-extraction experiments, and their stability was compared in terms of extraction rate and amount of $\mathrm{Zn}$ (II) extracted. In each case back-extraction was very fast and virtually complete stripping of $\mathrm{Zn}$ (II) from the loaded membrane was observed (Figures S2 and S3, Supplementary Material). Figure 5 shows all five extraction curves for each membrane. The extraction performance of the non-cross-linked PIM (Figure 5b) decreased by 31\%, whereas this decrease for the cross-linked PIM was only 7\% (Figure 5a). In addition, the non-cross-linked PIM (i.e., 40 $\mathrm{wt} \%$ D2EHPA, $10 \mathrm{wt} \%$ NPOE and $50 \mathrm{wt} \%$ CTA) started to become physically deformed (i.e., wrinkled around the edges) and opaque after the second cycle (Figure S4, Supplementary Material) due to the accumulation of a precipitate. It was hypothesized that this precipitate was the leached-out Zn-D2EHPA complex which was confirmed by AAS measurements indicating the presence of $\mathrm{Zn}$ in the precipitate. Hence, it was concluded that the cross-linked PIM showed superior extraction efficiency and stability in comparison with the non-crosslinked PIM. 

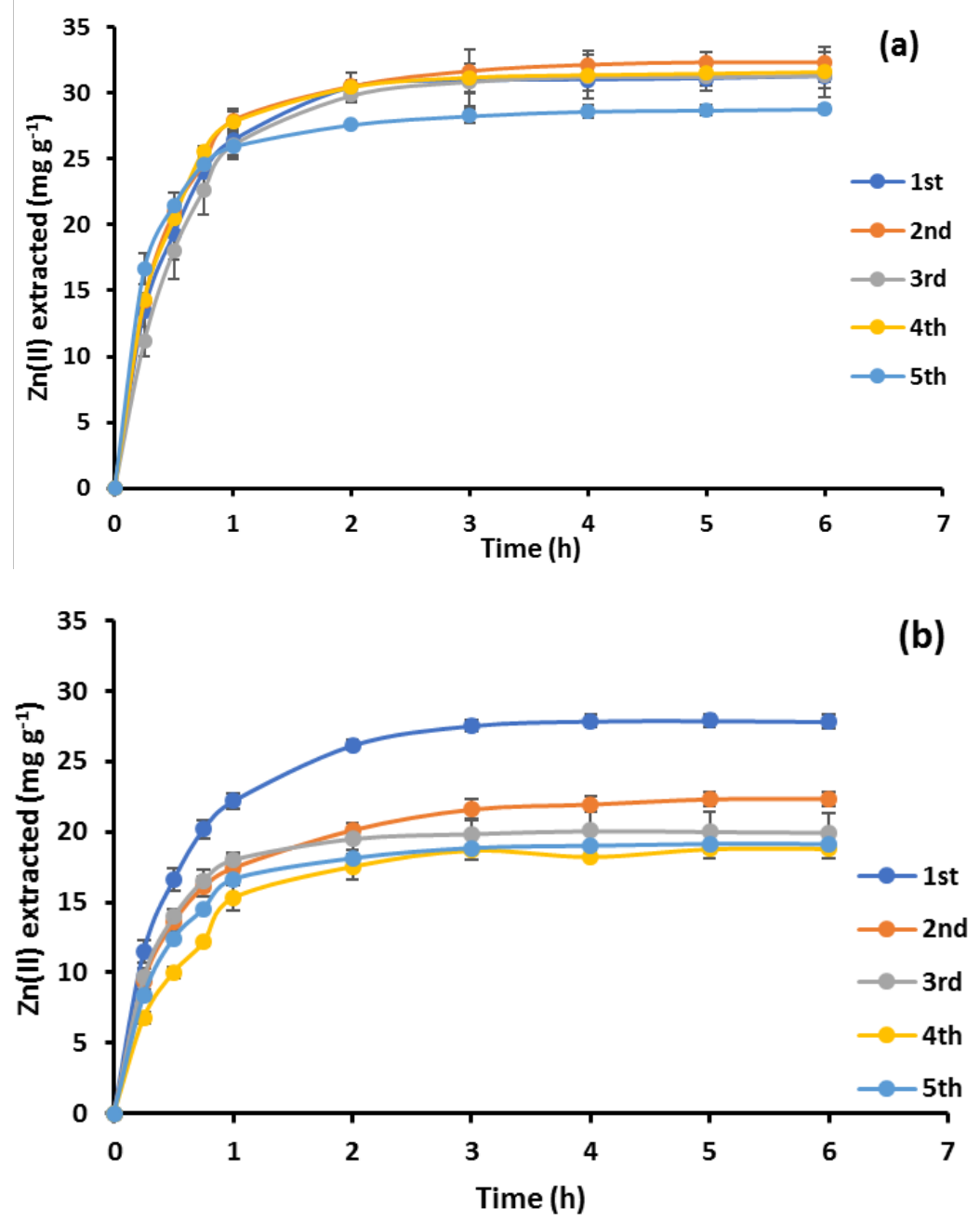

Figure 5. Transient Zn(II) concentrations in a cross-linked (a) and a non-cross-linked (b) CTA-based PIM (mg $\mathrm{Zn}(\mathrm{II})$ per g PIM) for five consecutive extraction experiments. D2EHPA concentration, $40 \mathrm{wt} \%$; NPOE concentration, $10 \mathrm{wt} \%$; polymers ratio, $6: 4$; initiator concentration, $0.6 \mathrm{wt} \%$; feed solution, $100 \mathrm{~mL}$ of $30 \mathrm{mg} \mathrm{L}^{-1} \mathrm{Zn}(\mathrm{II})$ at $\mathrm{pH} 3$; receiving solution, $1.0 \mathrm{M} \mathrm{HCl}$. Error bars, $\pm \mathrm{SD}(\mathrm{n}=3)$.

It was also observed that in the second extraction experiment the cross-linked PIM extracted a slightly higher amount of $\mathrm{Zn}$ (II) (32.3 $\left.\mathrm{mg} \mathrm{g}^{-1}\right)$ than in the first extraction experiment (31.2 $\left.\mathrm{mg} \mathrm{g}^{-1}\right)$ despite a 12\% mass loss after the first extraction/back-extraction cycle. With the aim of finding an explanation for this observation, the feed and receiving solutions after the first and second cycles were analyzed by mass spectrometry and the corresponding spectra are shown in Figure 6a. The mass spectrum of the feed solution after the first extraction experiment showed peaks with high intensity at 441, 485 and $529(\mathrm{~m} / \mathrm{z})$, which corresponded to the presence of PEG-DMA (Figure 5Sa). Peaks at 323 and $645(\mathrm{~m} / \mathrm{z})$ were also identified, corresponding to the presence of D2EHPA, although their intensity was significantly lower than that of the PEG-DMA peaks. In the feed solution after the second extraction experiment, no PEG-DMA peaks were observed and the D2EHPA peaks were still present as in the feed solution after the first extraction experiment (Figure 6b). 

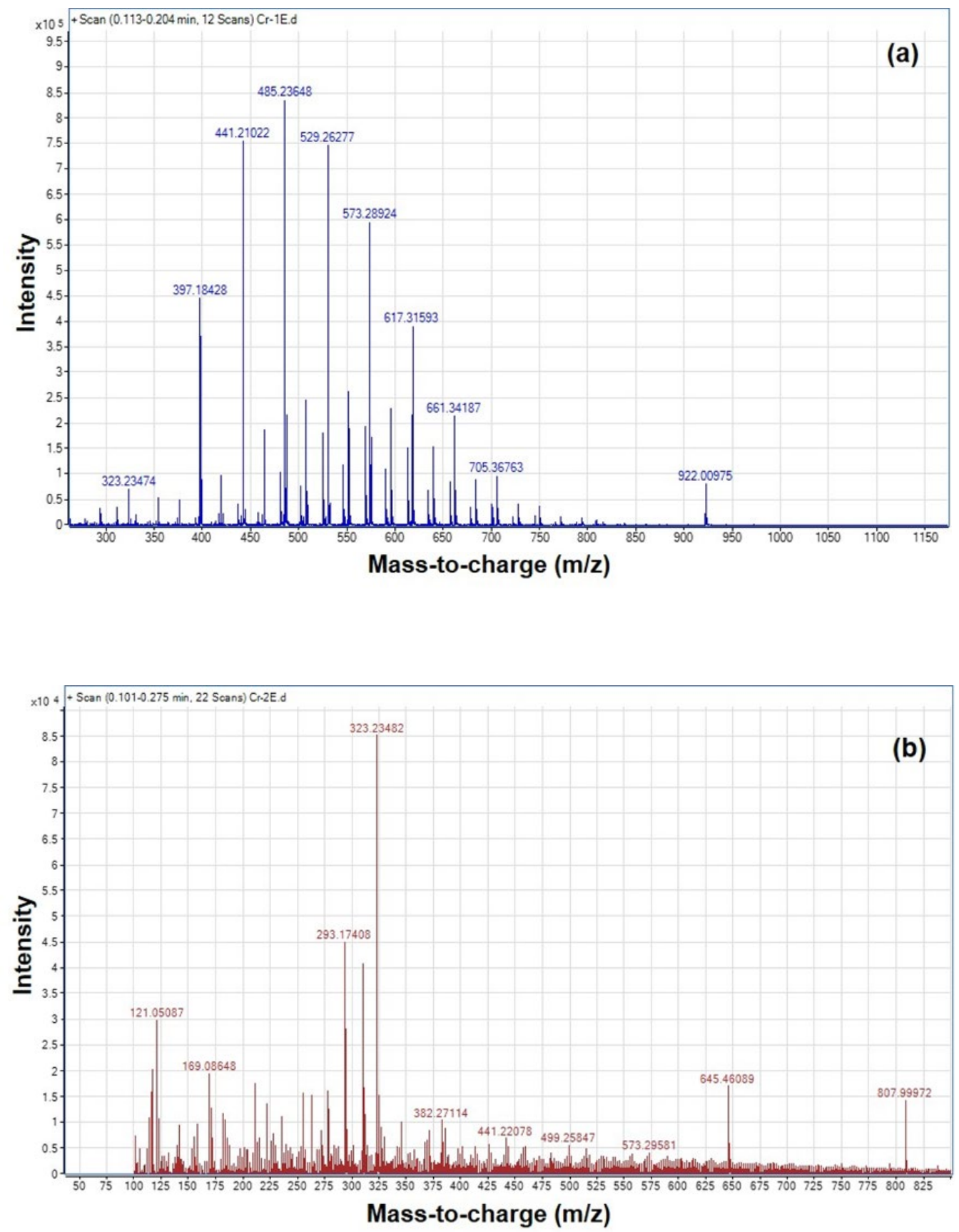

Figure 6. Mass spectra of the feed solution after the first (a) and second (b) extraction experiments involving the same cross-linked membrane (PIM 5, Table 1).

It should be noted that no peaks corresponding to either PEG-DMA or D2EHPA were observed in the mass spectra of the back-extraction solutions, and no peaks related to NPOE were identified in any of the solutions. This analysis indicated that the mass loss of $12 \%$ recorded after the first cycle was mostly due to the loss of un-crosslinked PEG-DMA present in the membrane. The loss of PEG-DMA during Zn(II) extraction can be avoided by washing the membrane with a mildly acidic solution (to prevent D2EHPA loss by reducing its solubility) before its use in extraction/transport experiments. It was assumed that the un-crosslinked PEGDMA impeded to some extent the extraction of $\mathrm{Zn}(\mathrm{II})$ and, therefore, its loss to the feed solution in the first cycle resulted in a higher initial flux value (i.e., $1.2 \times 10^{-5}$ and $1.5 \times 10^{-5} \mathrm{~mol} \mathrm{~m}^{-2} \mathrm{~s}^{-1}$ for the $1^{\text {st }}$ and $2^{\text {nd }}$ cycles, 
respectively) and a slightly higher amount of $\mathrm{Zn}$ (II) extracted despite the fact a small amount of D2EHPA was lost (about 2\%) in the first cycle. From the second cycle onwards, there was no loss of PEG-DMA, however, small amounts of D2EHPA (i.e., 2-3\%) leached into the feed solution during each subsequent cycle (Figure 7), which was most likely responsible for the relatively small decrease in the amount of $\mathrm{Zn}$ (II) extracted in

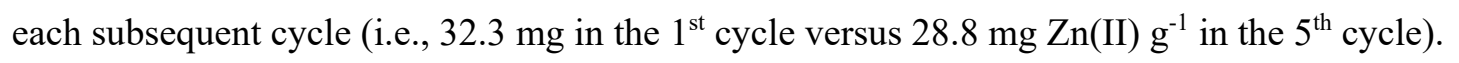

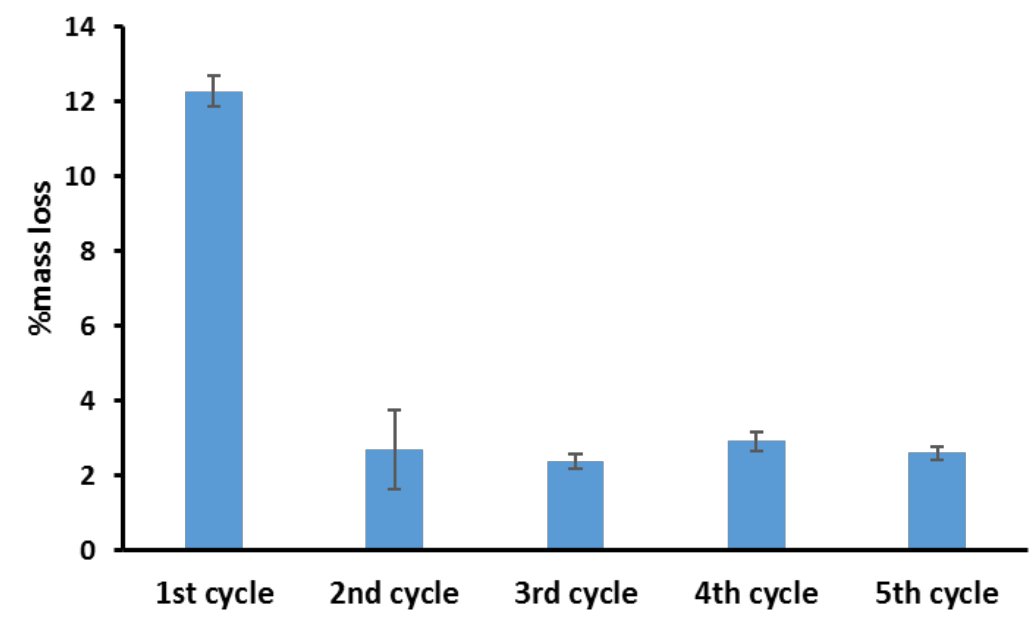

Figure 7. Percentage mass loss of a cross-linked CTA-based PIM (PIM 5) during the stability study (i.e., five consecutive extraction and back-extraction cycles). Error bars, \pm SD $(n=3)$.

\subsection{Surface morphology analysis}

\subsubsection{Cross-linked vs. non-cross-linked CTA-based PIMs}

Due to good extraction efficiency and stability, the surface morphology of the cross-linked PIM 5 (Table 1) and its non-cross-linked counterpart (i.e., $40 \mathrm{wt} \%$ D2EHPA, 10\% NPOE and 50\% CTA) was studied using AFM. Typical constant force AFM topographs are shown in Figure 8. There are distinguishable morphological differences between the cross-linked and non-cross-linked membranes.

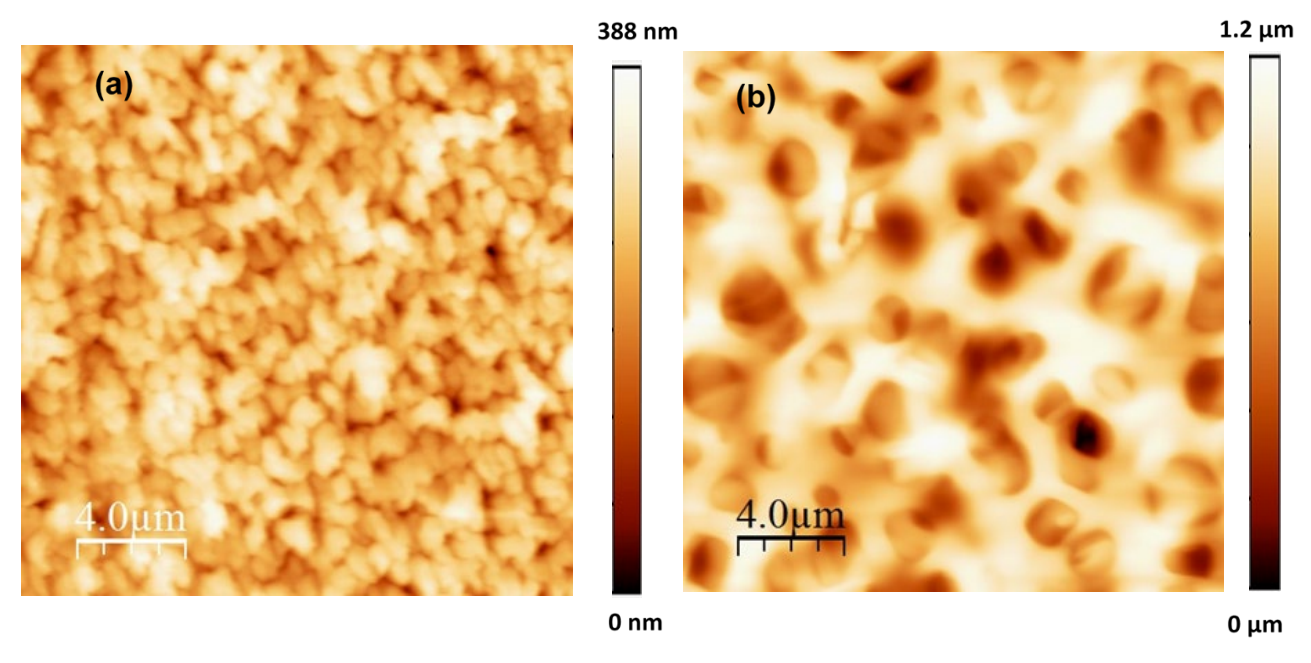

Figure 8. Constant force AFM topographs of a cross-linked (a) and non-cross-linked (b) membrane (crosslinked PIM composition: $40 \mathrm{wt} \%$ D2EHPA, $10 \mathrm{wt} \%$ NPOE, polymers ratio 6:4, $0.6 \mathrm{wt} \%$ initiator; non-crosslinked PIM composition: $40 \mathrm{wt} \%$ D2EHPA, $10 \mathrm{wt} \%$ NPOE, $50 \mathrm{wt} \% \mathrm{CTA})$. 
Figure 8a clearly shows that the cross-linked PIM exhibits granular like features and the corresponding voids between the granules are as deep as $400 \mathrm{~nm}$ relative to their tops, whereas the non-cross-linked membrane appears as a smooth film with deeper dents (as deep as $1200 \mathrm{~nm}$ ) in comparison with the cross-linked PIM. In order to assess the surface area of the membranes, the granule/void density was calculated, and is shown in Table 2 and Figure 9. For the non-cross-linked membrane, 11 voids per $100 \mu^{2}$ were found in which approximately $10 \%$ of the voids were around $800-900 \mathrm{~nm}$, and the remaining varied from $250-500 \mathrm{~nm}$ (Table 2; Figure 9b). On the other hand, in the cross-linked membrane about four times more voids were identified, well distributed throughout the PIM surface, with an average depth of 150-250 nm (Table 2; Figure 9a). Even though the cross-linked PIM's voids were shallower than those of its non-cross-linked counterpart, they provided a larger effective surface area compared to the cross-linked PIM due to their much higher number which resulted in higher PIM flexibility and extraction rate in comparison with the non-cross-linked PIM (Figure 3a).

Table 2. Analysis of the PIM voids in the AFM topographs of the cross-linked and non-cross-linked PIMs.

\begin{tabular}{lcc}
\hline Type of PIM & Number of voids $\left(\right.$ per $\left.\mathbf{1 0 0} \boldsymbol{\mu m}^{\mathbf{2}}\right)$ & Area covered by the voids $\left(\boldsymbol{\mu m}^{\mathbf{2}}\right)$ \\
\hline Cross-linked PIM (PIM 5) & 48 & 20 \\
Non-cross-linked PIM & 11 & 27 \\
\hline
\end{tabular}
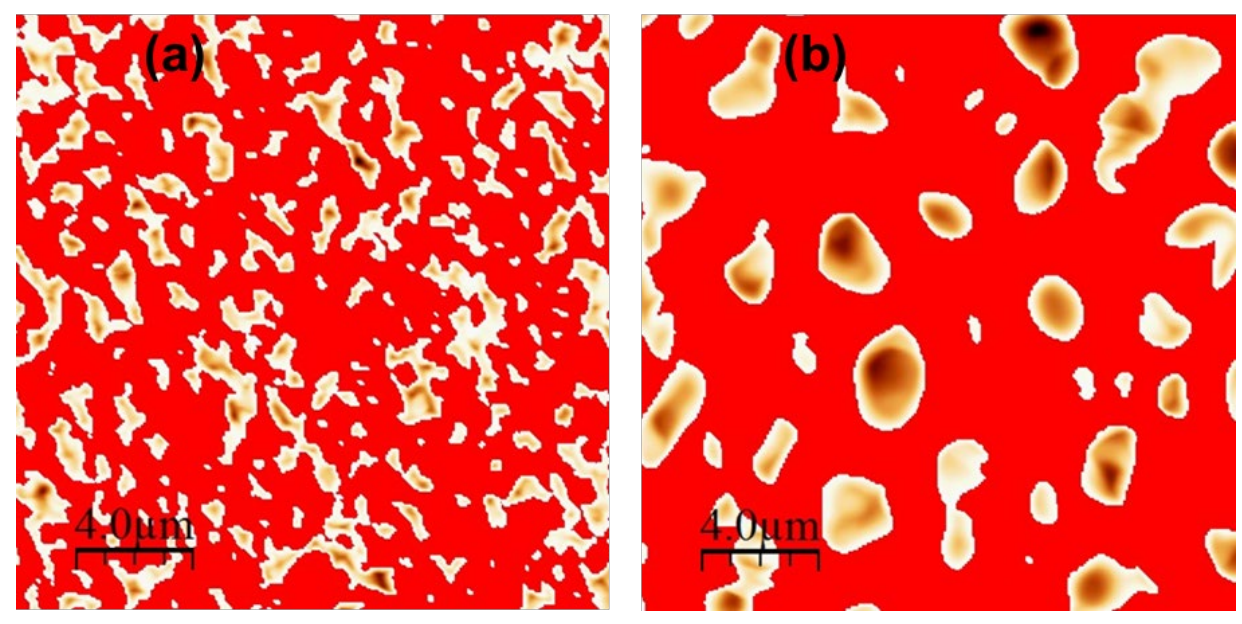

Figure 9. Contrast saturated AFM topographs of a cross-linked (a) and non-cross-linked (b) membrane. The voids present in cross-linked and non-cross-linked membranes are clearly visible (cross-linked PIM composition: $40 \mathrm{wt} \%$ D2EHPA, $10 \mathrm{wt} \%$ NPOE, polymers ratio 6:4, $0.6 \mathrm{wt} \%$ initiator; non-cross-linked PIM composition: $40 \mathrm{wt} \%$ D2EHPA, $10 \mathrm{wt} \%$ NPOE, $50 \mathrm{wt} \%$ CTA).

\subsubsection{Effect of the amount of plasticizer on the surface morphology of the cross-linked CTA-based PIMs}

In general, the role of the plasticizer in PIMs is to penetrate the base-polymer chains and decrease the intermolecular forces, leading to a decrease in the glass transition temperature of the polymer which results in a more flexible membrane. Hence, the plasticizer concentration in the membrane is important: if it is too low the membrane will be too rigid and if it is too high the membrane will be too soft and mechanically unstable, 
and moreover the plasticizer tends to exude to the membrane surface. In order to assess the effect of the plasticizer concentration on the surface morphology of cross-linked membranes, PIMs containing $40 \mathrm{wt} \%$ D2EHPA and 5, 10 or $20 \mathrm{wt} \%$ NPOE (Table 1, PIMs 4, 5 and 6), were imaged by AFM (Figures 10a-10c). The AFM topographs show that the three PIMs mentioned above are morphologically similar and consist of interconnected granules. However, the size of the granules gradually decreased as the NPOE concentration in the membrane was increased as a result of more NPOE penetrating the polymer chains thus making them slightly more flexible which resulted in smoother PIM surfaces and higher initial flux values (Figure 10d).

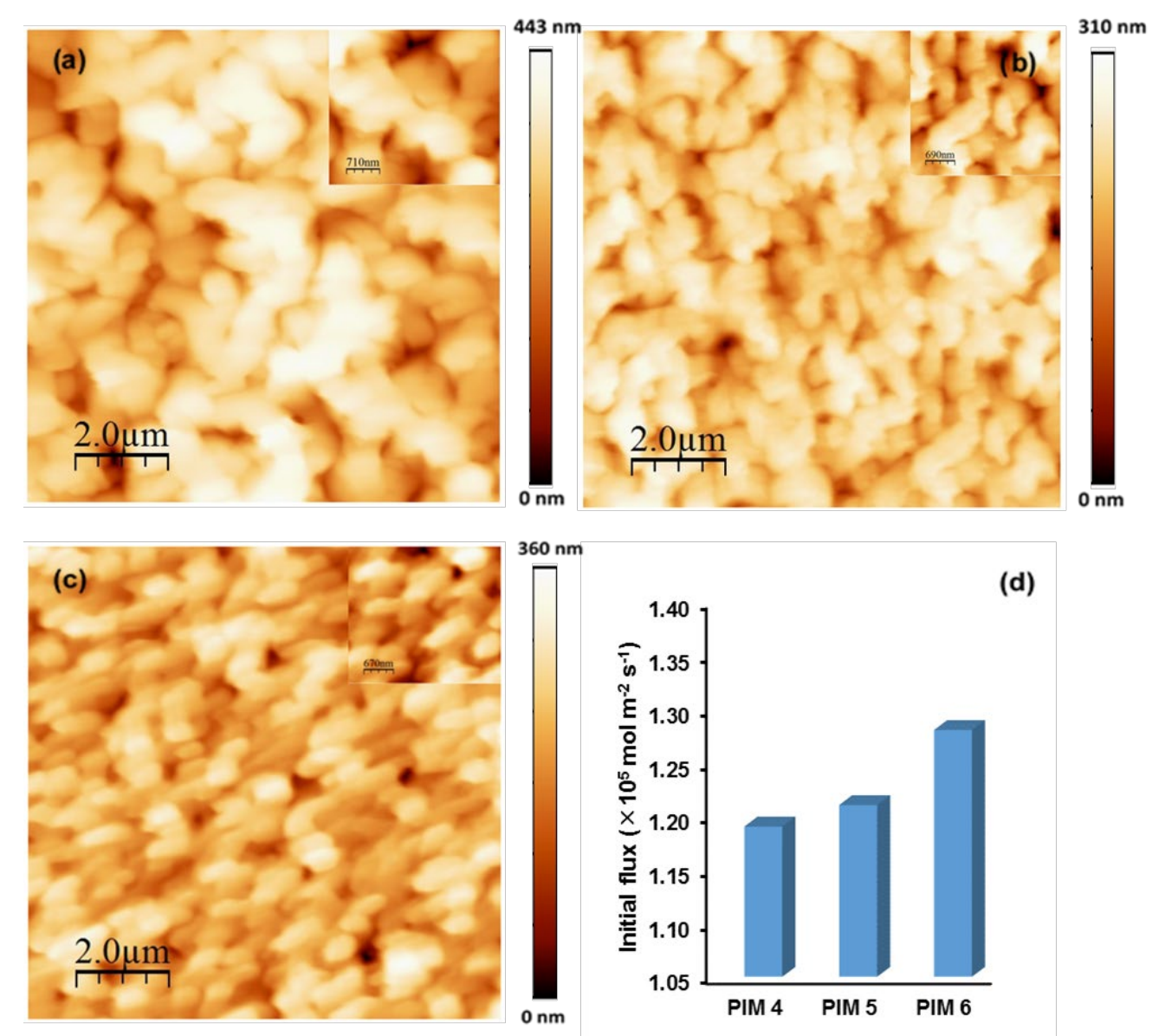

Figure 10. Constant force AFM topographs of cross-linked membranes containing different NPOE concentrations: (a) $5 \mathrm{wt} \%$, (b) $10 \mathrm{wt} \%$ and (c) $20 \mathrm{wt} \%$, and the corresponding initial flux values (d). D2EHPA concentration, $40 \mathrm{wt} \%$ D2EHPA; polymers ratio (CTA:PEG-DMA), 6:4; initiator (DMPA) concentration, $0.6 \mathrm{wt} \%$.

\subsection{Interference study}

In environmental or industrial waters common base metal ions, such as $\mathrm{Cd}(\mathrm{II}), \mathrm{Co}(\mathrm{II}), \mathrm{Ni}(\mathrm{II})$, and $\mathrm{Fe}(\mathrm{III})$, will also be present along with $\mathrm{Zn}(\mathrm{II})$. Therefore, selectivity is a very important parameter for assessing the suitability of the newly developed PIM for environmental or industrial applications. 
An interference study was conducted using the cross-linked CTA-based PIM (PIM 5, Table 1), which provided a good extraction performance and the best long-term stability. This PIM was thus immersed in $100 \mathrm{~mL}$ of feed solution containing $\mathrm{Zn}(\mathrm{II}), \mathrm{Co}(\mathrm{II}), \mathrm{Ni}(\mathrm{II}), \mathrm{Cd}(\mathrm{II})$, and $\mathrm{Cu}(\mathrm{II})$ at $30 \mathrm{mg} \mathrm{L}^{-1}$ concentration each and $\mathrm{pH} 3$. Figure 11a clearly indicates that $\mathrm{Zn}(\mathrm{II})$ was preferentially extracted into the membrane with minimal interference from the other base metal ions. Since these base metal ions can also be present at concentrations higher than that of $\mathrm{Zn}$ (II), the selectivity of the newly developed cross-linked PIM was also assessed when the concentrations of the interferents were five times higher than the $\mathrm{Zn}$ (II) concentration (i.e., feed solution containing $30 \mathrm{mg} \mathrm{L}^{-1} \mathrm{Zn}(\mathrm{II})$ and $150 \mathrm{mg} \mathrm{L}^{-1} \mathrm{Co}(\mathrm{II}), \mathrm{Ni}(\mathrm{II}), \mathrm{Cd}(\mathrm{II})$, and $\mathrm{Cu}(\mathrm{II})$ each). Even under these conditions the interference was relatively insignificant (Figure 11b). These results confirmed the high selectivity of the CTA/D2EHPA cross-linked PIM towards $\mathrm{Zn}$ (II), showing that $\mathrm{Zn}$ (II) could be extracted selectively in the presence of a mixture of different base metal ions commonly present in environmental and industrial waters.
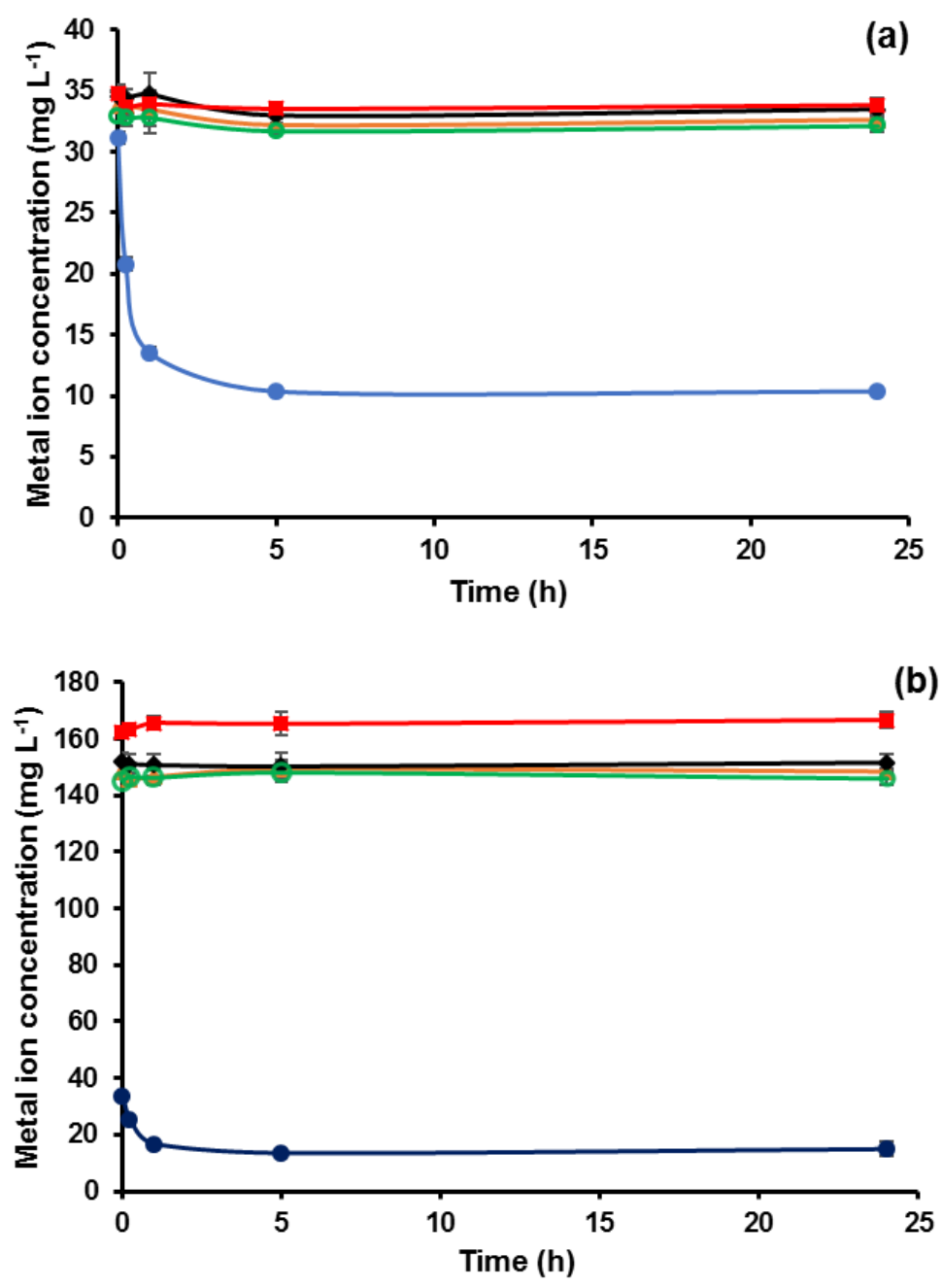

Figure 11. Transient concentrations of $(\bullet) \mathrm{Zn}(\mathrm{II}),(\bullet) \mathrm{Cd}(\mathrm{II}),(\Delta) \mathrm{Co}(\mathrm{II}),(\diamond) \mathrm{Cu}(\mathrm{II})$, and (O) $\mathrm{Ni}(\mathrm{II})$ in the feed solutions at pH 3 in which the potential interfering metal ions have the same concentration as $\mathrm{Zn}$ (II) (a) or have a concentration five times higher than that of $\mathrm{Zn}$ (II) (b). Cross-linked PIM composition, $40 \mathrm{wt} \%$ D2EHPA, $10 \mathrm{wt} \%$ NPOE, CTA:PEG-DMA 6:4, $0.6 \mathrm{wt} \%$ initiator; feed solution, $100 \mathrm{~mL}$ of $30 \mathrm{mg} \mathrm{L}^{-1}$ of each metal ion (a) and $30 \mathrm{mg} \mathrm{L}^{-1} \mathrm{Zn}(\mathrm{II})$ and $150 \mathrm{mg} \mathrm{L}^{-1}$ for each interferent (b). 
$\mathrm{Fe}(\mathrm{III})$ is commonly present in industrial and environmental waters and has been reported to interfere with $\mathrm{Zn}(\mathrm{II})$ extraction when using D2EHPA-based PIMs [31]. In the same study the Fe(III) interference was successfully eliminated by adding disodium hydrogen phosphate $\left(\mathrm{Na}_{2} \mathrm{HPO}_{4}\right)$ to the feed solution in a 1:3 mole ratio (Fe(III): $\mathrm{Na}_{2} \mathrm{HPO}_{4}$ ) in order to precipitate $\mathrm{Fe}(\mathrm{III})$ and thus avoid its extraction by the PIM. The same approach was applied in the present study. The results obtained confirmed the Fe(III) interference in the absence of $\mathrm{Na}_{2} \mathrm{HPO}_{4}$, and also demonstrated that in the presence of $\mathrm{Na}_{2} \mathrm{HPO}_{4}$ the interference of $\mathrm{Fe}(\mathrm{III})$ could be eliminated and $\mathrm{Zn}(\mathrm{II})$ could be extracted to the same extent as if $\mathrm{Fe}(\mathrm{III})$ were not present (Figure 12).

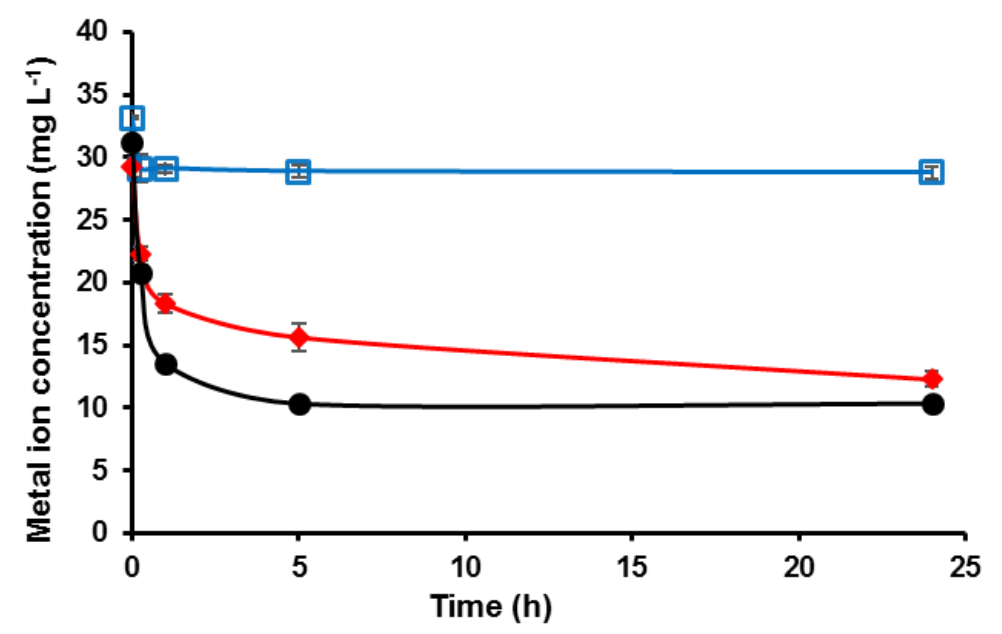

Figure 12. Transient concentrations of $\mathrm{Zn}(\mathrm{II})(\square)$ and $\mathrm{Fe}(\mathrm{III})(\diamond)$ in a feed solution containing $30 \mathrm{mg} \mathrm{L}^{-1}$ of each ion, and of $\mathrm{Zn}(\mathrm{II})(\bullet)$ in a feed solution of the same Fe(III) and $\mathrm{Zn}$ (II) composition in the presence of $\mathrm{Na}_{2} \mathrm{HPO}_{4}$. Cross-linked PIM composition, $40 \mathrm{wt} \%$ D2EHPA, $10 \mathrm{wt} \%$ NPOE, CTA : PEG-DMA 6:4, 0.6 wt\% initiator. Error bars, $\pm \operatorname{SD}(\mathrm{n}=3)$.

\subsection{Transport of $\mathrm{Zn}(I I)$}

One of the main advantages of PIM-based separation over conventional solvent extraction stems from the possibility of conducting the extraction and back-extraction processes at the feed and receiving sides of the PIM, respectively, simultaneously. This capability of PIMs, in combination with their facilitated transmembrane mass transport mechanism [1,2], allows the complete transport of the target chemical species (in this case $\mathrm{Zn}(\mathrm{II})$ ) from the feed to the receiving solution. To demonstrate this capability of PIM-based separation, transport experiments were carried out using the cross-linked PIM with best extraction performance which was composed of $40 \mathrm{wt} \%$ D2EHPA, $10 \mathrm{wt} \%$ NPOE, and CTA:PEG-DMA 6:4, and $0.6 \mathrm{wt} \%$ initiator. Feed solutions containing 27,46 or $65 \mathrm{mg} \mathrm{L}^{-1} \mathrm{Zn}$ (II) at $\mathrm{pH} 3$ and receiving solutions containing $1.0 \mathrm{M} \mathrm{HCl}$ were used in these experiments. The transient $\mathrm{Zn}$ (II) concentrations in the feed and receiving solutions, shown in Figure 13, clearly indicate that the newly developed cross-linked membrane is capable of practically completely (i.e., $98.9 \pm 0.9 \%, 93.6 \pm 1.0 \%$ and $97.2 \pm 2.1 \%$ for initial $\mathrm{Zn}$ (II) concentrations of 27, 46 and $65 \mathrm{mg}$ $\mathrm{L}^{-1}$, respectively) transporting $\mathrm{Zn}$ (II) from the feed solution to the receiving solution in about $3 \mathrm{~h}$ under the experimental conditions used. The thickness of the membrane decreased insignificantly from $55 \pm 2 \mu \mathrm{m}$ to $52 \pm 2$ $\mu \mathrm{m}$ after completing the transport experiments which was, most likely, due to the leaching of un-crosslinked PEG-DMA from the membrane into the adjacent aqueous phases. 


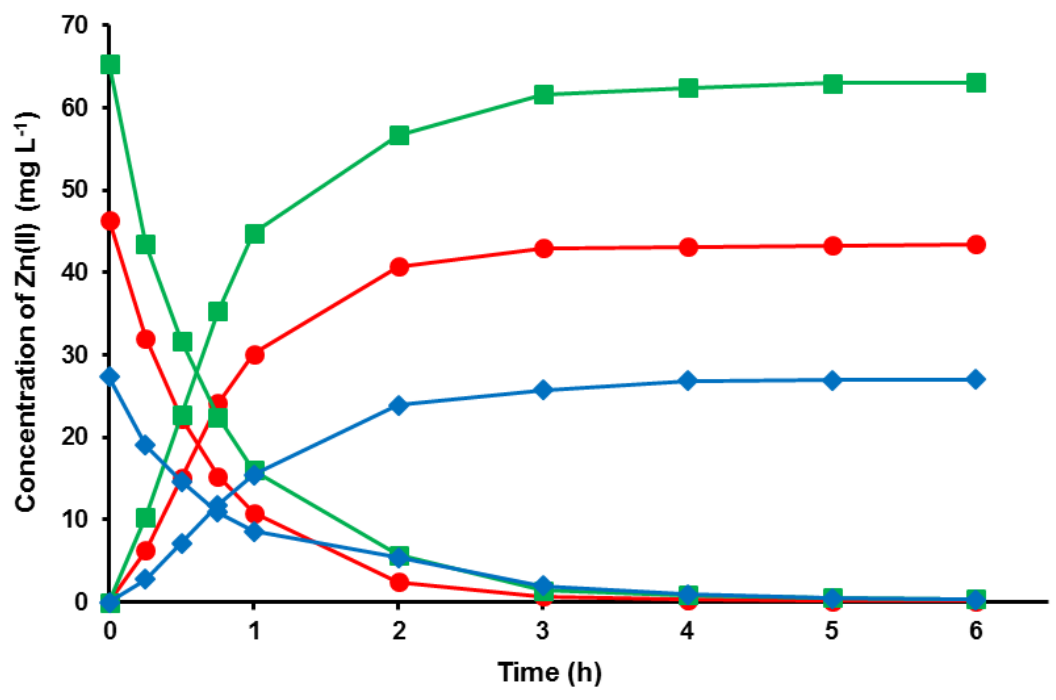

Figure 13. Transient $\mathrm{Zn}(\mathrm{II})$ concentrations in the feed solutions $(100 \mathrm{~mL})$ containing initially $65(\square), 46$ $(\bullet)$ and $27(\bullet) \mathrm{mg} \mathrm{L}^{-1}$ of $\mathrm{Zn}(\mathrm{II})$ at $\mathrm{pH} 3$ and in the respective receiving solutions (100 mL) during transport experiments using the cross-linked CTA-based PIM with D2EHPA concentration of $40 \mathrm{wt} \%$, NPOE concentration of $10 \mathrm{wt} \%$, polymers ratio of $6: 4$, and initiator concentration of $0.6 \mathrm{wt} \%$. The receiving solution contained 1.0 M HCl. Transport experiments were performed in duplicate.

\section{Conclusions}

On the basis of the results obtained it was concluded that depending on the nature of the base polymer and cross-linking polymer, cross-linked PIMs can exhibit superior stability, extraction rate and extractive capacity compared to their non-cross-linked counterparts.

A screening of the base-polymers PVC, CTA and PVDF-HFP for their suitability in preparing cross-linked PIMs was performed. Of these, PVC showed to be unsuitable for cross-linking with PEG-DMA due to polymer incompatibility. Successful cross-linked PIMs were prepared with both PVDF-HFP and CTA, however, the CTA-based PIM provided superior Zn(II) extraction performance in comparison to both the cross-linked PVDF-HFP-based PIM and its CTA-based non-cross-linked counterpart. The effect of the concentrations of both the carrier D2EHPA and plasticizer NPOE in the cross-linked CTA-based PIM was studied, and the membrane composed of $40 \mathrm{wt} \%$ D2EHPA, $10 \mathrm{wt} \%$ NPOE, $0.6 \mathrm{wt} \%$ DMPA with a base-polymer to crosslinking polymer mass ratio of $6: 4$ was found to have the highest extraction rate in addition to showing very good stability over five consecutive extraction/back-extraction cycles. Limited mass loss of the PIM was observed during the first cycle which was proven by mass spectrometric analysis of the feed solution to be due to the loss of un-crosslinked PEG-DMA. The stability of the cross-linked CTA-based PIM was shown to be significantly superior compared to its non-cross-linked counterpart. It also exhibited high selectivity for Zn(II) at $\mathrm{pH} 3$ in the presence of other commonly encountered in industrial and environmental waters base metal ions at concentrations 5 times higher than that of $\mathrm{Zn}(\mathrm{II})$. 
AFM surface imaging of both cross-linked and non-cross-linked CTA-based PIMs showed that the crosslinked PIM surface displayed a large number of shallow voids and these voids became smaller in size as the NPOE concentration was increased, while the non-cross-linked PIMs contained a small number of deeper voids. The specific surface area of the cross-linked PIM was found to be larger than that of its non-cross-linked counterpart which could explain the faster rate of extraction with cross-linked PIMs.

The PIM with best extraction performance transported practically completely $\mathrm{Zn}(\mathrm{II})$ from a feed solution at pH 3 to a receiving solution containing $1.0 \mathrm{M} \mathrm{HCl}$ which involved simultaneous extraction of $\mathrm{Zn}(\mathrm{II})$ at the $\mathrm{PIM} /$ feed solution interface, its back-extraction at the PIM/receiving solution interface and facilitated transport of $\mathrm{Zn}(\mathrm{II})$ across the membrane. 


\section{References}

[1] M.I.G.S. Almeida, R.W. Cattrall, S.D. Kolev, Recent trends in extraction and transport of metal ions using polymer inclusion membranes (PIMs), Journal of Membrane Science, 415-416 (2012) 9-23.

[2] L. Nghiem, P. Mornane, I. Potter, J. Perera, R. Cattrall, S. Kolev, Extraction and transport of metal ions and small organic compounds using polymer inclusion membranes (PIMs), Journal of Membrane Science, 281 (2006) 7-41.

[3] C. Fontàs, R. Tayeb, M. Dhahbi, E. Gaudichet, F. Thominette, P. Roy, K. Steenkeste, M.-P. FontaineAupart, S. Tingry, E. Tronel-Peyroz, Polymer inclusion membranes: The concept of fixed sites membrane revised, Journal of Membrane Science, 290 (2007) 62-72.

[4] M. Baczynska, M. Regel-Rosocka, M.T. Coll, A. Fortuny, A.M. Sastre, M. Wisniewski, Transport of $\mathrm{Zn}(\mathrm{II}), \mathrm{Fe}(\mathrm{II}), \mathrm{Fe}$ (III) across polymer inclusion membranes (PIM) and flat sheet supported liquid membranes (SLM) containing phosphonium ionic liquids as metal ion carriers, Separation Science and Technology, 51 (2016) 2639-2648.

[5] H.P. Duan, Z.Z. Wang, X.H. Yuan, S.X. Wang, H. Guo, X.J. Yang, A novel sandwich supported liquid membrane system for simultaneous separation of copper, nickel and cobalt in ammoniacal solution, Sepuration and Purification Technology, 173 (2017) 323-329.

[6] H.P. Duan, S.X. Wang, X.J. Yang, X.H. Yuan, Q. Zhang, Z.J. Huang, H. Guo, Simultaneous separation of copper from nickel in ammoniacal solutions using supported liquid membrane containing synergistic mixture of M5640 and TRPO, Chemical Engineering Research \& Design, 117 (2017) 460471.

[7] K. Staszak, A. Wojciechowska, M.T.A. Reis, I. Wojciechowska, K. Wieszczycka, M.R.C. Ismael, J.M.R. Carvalho, Recovery of zinc(II) from chloride solutions using pseudo-emulsion based hollow fiber strip dispersion with pyridineketoxime extractants, Sepuration and Purification Technology, 177 (2017) 152-160.

[8] K. Wieszczycka, M. Regel-Rosocka, K. Staszak, A. Wojciechowska, M.T.A. Reis, M.R.C. Ismael, M.L.F. Gameiro, J.M.R. Carvalho, Recovery of zinc(II) from chloride solutions using pseudoemulsion based hollow fiber strip dispersion (PEHFSD) with 1-(3-pyridyl)undecan-1-one oxime or tributylphosphate, Sepuration and Purification Technology, 154 (2015) 204-210.

[9] F.J. Alguacil, Non-dispersive extraction of gold(III) with ionic liquid Cyphos IL101, Sepuration and Purification Technology, 179 (2017) 72-76.

[10] M. Baczynska, M. Waszak, M. Nowicki, D. Przadka, S. Borysiak, M. Regel-Rosocka, Characterization of Polymer Inclusion Membranes (PIMs) Containing Phosphonium Ionic Liquids as Zn(II) Carriers, Industrial \& Engineering Chemistry Research, 57 (2018) 5070-5082.

[11] M. Ulewicz, E. Radzyminska-Lenarcik, Application of polymer and supported membranes with 1decyl-4-methylimidazole for pertraction of transition metal ions, Sepuration and Purification Technology, 49 (2014) 1713-1721.

[12] D. Kogelnig, A. Regelsberger, A. Stojanovic, F. Jirsa, R. Krachler, B.K. Keppler, A polymer inclusion membrane based on the ionic liquid trihexyl(tetradecyl)phosphonium chloride and PVC for solidliquid extraction of $\mathrm{Zn}$ (II) from hydrochloric acid solution, Monatshefte für Chemie - Chemical Monthly, 142 (2011) 769-772.

[13] L.L. Zhang, R.W. Cattrall, M. Ashokkumar, S.D. Kolev, On-line extractive separation in flow injection analysis based on polymer inclusion membranes: a study on membrane stability and approaches for improving membrane permeability, Talanta, 97 (2012) 382-387.

[14] M. Ulewicz, J. Szczygelska-Tao, J.F. Biernat, Selectivity of Pb(II) transport across polymer inclusion membranes doped with imidazole azothiacrown ethers, Journal of Membrane Science, 344 (2009) 3238.

[15] G. Salazar-Alvarez, A.N. Bautista-Flores, E.R.D. Miguel, M. Muhammed, J. de Gyves, Transport characterisation of a PIM system used for the extraction of $\mathrm{Pb}(\mathrm{II})$ using D2EHPA as carrier, Journal of Membrane Science, 250 (2005) 247-257.

[16] Y. Cho, C. Xu, R.W. Cattrall, S.D. Kolev, A polymer inclusion membrane for extracting thiocyanate from weakly alkaline solutions, Journal of Membrane Science., 367 (2011) 85-90.

[17] H. Matsuoka, M. Aizawa, S. Suzuki, Uphill transport of uranium across a liquid membrane, Journal of Membrane Science, 7 (1980) 11-19.

[18] A. Kaya, C. Onac, H.K. Alpoguz, S. Agarwal, V.K. Gupta, N. Atar, A. Yilmaz, Reduced graphene oxide based a novel polymer inclusion membrane: Transport studies of $\mathrm{Cr}(\mathrm{VI})$, Journal of Molecular Liquids, 219 (2016) 1124-1130. 
[19] Y. O'Bryan, Y.B. Truong, R.W. Cattrall, I.L. Kyratzis, S.D. Kolev, A new generation of highly stable and permeable polymer inclusion membranes (PIMs) with their carrier immobilized in a crosslinked semi-interpenetrating polymer network. Application to the transport of thiocyanate, Journal of Membrane Science, 529 (2017) 55-62.

[20] K.A. Walker, L.J. Markoski, G.A. Deeter, G.E. Spilman, D.C. Martin, J.S. Moore, Cross-linking chemistry for high-performance polymer networks, Polymer, 35 (1994) 5012-5017.

[21] C. Decker, Recent developments in photoinitiated radical polymerization, Macromolecular Symposia, 143 (1999) 45-63.

[22] K.Y. Suh, R. Langer, J. Lahann, A novel photodefinable reactive polymer coating and its use for microfabrication of hydrogel elements, Advanced Materials, 16 (2004) 1401-1405.

[23] T. Fourniols, L.D. Randolph, A. Staub, K. Vanvarenberg, J.G. Leprince, V. Preat, A. des Rieux, F. Danhier, Temozolomide-loaded photopolymerizable PEG-DMA-based hydrogel for the treatment of glioblastoma, Journal Controlled Release, 210 (2015) 95-104.

[24] C. Decker, F. Morel, S. Jonsson, S. Clark, C. Hoyle, Light-induced polymerisation of photoinitiatorfree vinyl ether maleimide systems, Macromolecular Chemistry and Physics, 200 (1999) 1005-1013.

[25] K. Arcaute, B. Mann, R. Wicker, Stereolithography of spatially controlled multi-material bioactive poly (ethylene glycol) scaffolds, Acta Biomaterialia, 6 (2010) 1047-1054.

[26] S. Bäckström, J. Benavente, R.W. Berg, K. Stibius, M.S. Larsen, H. Bohr, C. Hélix-Nielsen, Tailoring properties of biocompatible PEG-DMA hydrogels with UV light, Materials Sciences and Applications, 3 (2012) 425.

[27] T.-J. Jeon, N. Malmstadt, J.J. Schmidt, Hydrogel-encapsulated lipid membranes, Journal of the American Chemical Society, 128 (2006) 42-43.

[28] S. Petralito, R. Spera, S. Pacelli, M. Relucenti, G. Familiari, A. Vitalone, P. Paolicelli, M.A. Casadei, Design and development of PEG-DMA gel-in-liposomes as a new tool for drug delivery, Reactive and Functional Polymers, 77 (2014) 30-38.

[29] S. He, M.J. Yaszemski, A.W. Yasko, P.S. Engel, A.G. Mikos, Injectable biodegradable polymer composites based on poly (propylene fumarate) crosslinked with poly (ethylene glycol)dimethacrylate, Biomaterials, 21 (2000) 2389-2394.

[30] Y.Y.N. Bonggotgetsakul, R.W. Cattrall, S.D. Kolev, Recovery of gold from aqua regia digested electronic scrap using a poly (vinylidene fluoride-co-hexafluoropropene) (PVDF-HFP) based polymer inclusion membrane (PIM) containing Cyphos (R) IL 104, Journal of Membrane Science, 514 (2016) 274-281.

[31] S.D. Kolev, Y. Baba, R.W. Cattrall, T. Tasaki, N. Pereira, J.M. Perera, G.W. Stevens, Solid phase extraction of zinc(II) using a PVC-based polymer inclusion membrane with di(2ethylhexyl)phosphoric acid (D2EHPA) as the carrier, Talanta, 78 (2009) 795-799.

[32] A.M. St John, R.W. Cattrall, S.D. Kolev, Determination of the initial flux of polymer inclusion membranes, Separation and Purification Technology, 116 (2013) 41-45. 


\section{University Library}

\section{- M I N E R VA}

\section{A gateway to Melbourne's research publications}

Minerva Access is the Institutional Repository of The University of Melbourne

\section{Author/s:}

Hoque, B;Almeida, MIGS;Cattrall, RW;Gopakumar, TG;Kolev, SD

Title:

Effect of cross-linking on the performance of polymer inclusion membranes (PIMs) for the extraction, transport and separation of $\mathrm{Zn}(\mathrm{II})$

\section{Date:}

2019-11-01

\section{Citation:}

Hoque, B., Almeida, M. I. G. S., Cattrall, R. W., Gopakumar, T. G. \& Kolev, S. D. (2019). Effect of cross-linking on the performance of polymer inclusion membranes (PIMs) for the extraction, transport and separation of Zn(II). JOURNAL OF MEMBRANE SCIENCE, 589, https://doi.org/10.1016/j.memsci.2019.117256.

Persistent Link:

http://hdl.handle.net/11343/291520 